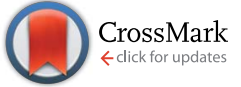

Cite this: RSC Adv., 2017, 7, 10215

Received 1st December 2016 Accepted 24th January 2017

DOI: $10.1039 / c 6 r a 27639 c$

rsc.li/rsc-advances

\section{Slowly released carbon source from composite materials system for removing nitrate pollution in groundwater}

\begin{abstract}
Yufeng Xie, ${ }^{\star a}$ Dejin Zhang, ${ }^{\text {ab }}$ Shuai Lou, ${ }^{\text {ac }}$ Fei He ${ }^{a}$ and Lu Yin ${ }^{\text {ad }}$
Chemoheterotrophic denitrification technologies using biopolymers as a solid carbon source and biofilm carriers have been widely trialed to remove nitrate from groundwater. Here, we use a polyhydroxyalkanoates (PHA) and cellulose blend as a slowly released carbon material, the performance of which was detected through static and dynamic experiments. In the static experiment, the carbon released from the straw, cob and bagasse was $66.95,40.12$ and $40.65 \mathrm{mg} \mathrm{L}^{-1}$, respectively. Results show that the straw possessed higher carbon content than the others. In the dynamic experiments, the PHA/cellulose blend exhibited excellent nitrate removal efficiency and less adverse effects in nitrite accumulation during stable operation. The nitrate nitrogen removal rate reduced from $99.80 \%$ to $73.13 \%$ as nitrate loading increased from 40 to $60 \mathrm{mg} \mathrm{L}^{-1}$. The microbial structure of a permeable reactive barrier (PRB) system was revealed by high-throughput sequencing analysis. Azospira, Rhizomicrobium and Acidovorax were found to be the predominant species in the PHA system after the system had stabilized. Our results highlight that the PHA/cellulose blend is an economically attractive carbon source with good denitrification performance.
\end{abstract}

\section{Introduction}

Nitrate pollution of groundwater resources has become a serious worldwide issue mainly due to the abuse of agrochemicals, industrial and domestic wastewater runoff, fecal waste leaching and recharge of sewage to receiving waters. ${ }^{1,2} \mathrm{~A}$ nitrate concentration of lower than $10 \mathrm{mg} \mathrm{L}^{-1}$ is designated by the US Environmental Protection Agency and $50 \mathrm{mg} \mathrm{L}^{-1}$ by the World Health Organization and European Economic Community to prevent the risks to human health. ${ }^{3}$ Therefore, the social and environmental concerns have led the development of strategies to reduce nitrate concentration.

Solid-phase denitrification which uses indissoluble solid materials as a carbon source for biological denitrification and carriers for biofilm growth, is considered as a promising approach to remove nitrate from groundwater due to the advantages of avoiding the risks of overdosing or insufficient dosing, simple process control and supervision, constant supply of reducing power and less secondary organic pollution for

${ }^{a}$ Nanjing Institute of Environmental Sciences, Ministry of Environmental Protection, Nanjing 210042, China. E-mail: pkuyufeng@163.com; Tel: +86 2585287232

${ }^{b}$ Jiangsu Key Laboratory of Chemical Pollution Control and Resources Reuse, School of Environmental and Biological Engineering, Nanjing University of Science and Technology, Nanjing 210094, China

'Jiangsu Radiation Environment Protection Consultation Center, Nanjing 210019, China

${ }^{d}$ School of Environmental Science and Engineering, Nanjing University of Information Science and Technology, Nanjing 210044, Jiangsu, China biopolymers. ${ }^{4}$ These insoluble solid carbon materials then fell into two classes. One is natural organic substances such as woods chips, wheat straw, cotton, maize cobs, reeds, etc. Another is synthetic biodegradable polymers involving polycaprolactone (PCL), polylactic acid (PLA), polybutylene succinate (PBS), poly-3hydroxybutyric acid (PHB) and poly-3-hydroxybutyrate-co-hyroxyvelate (PHBV).$^{4-6}$ However, because of the inadequate nutrition and carriers for microbe, natural cellulose materials could not maintain the long service life in nitrate removal. Volokita et al. ${ }^{7,8}$ used cracked newspaper and untreated short staple cotton as solid carbon source for denitrification and found that the removal efficiency of nitrate decreased with the fast consumption of newspaper and cotton because denitrifying bacteria could not grow on its surface. Soares et al. ${ }^{9}$ demonstrated that fresh additional wheat-straw could transitorily improve denitrification performance, with maximum denitrification rate of $53 \mathrm{mg} \mathrm{N}(\mathrm{L} \mathrm{d})^{-1}$. However, compared with the traditional carbon source, this approach displays several drawbacks, i.e., the high cost for biopolymers, the high concentration of dissolved organic carbon and dark colour in effluent, and relatively low overall denitrification efficiency. ${ }^{10}$ Therefore, development of low cost indissoluble solid materials with high bioavailability for microbial growth and high effluent quality has become challenges for solid-phase denitrification. Blending biodegradable plastics with the cheap organic substances such as straw, cob and bagasse is a potential approach to not only reduce the overall cost of the materials but also improve the properties and biodegradability. ${ }^{\mathbf{1 1 , 1 2}}$ The straw, cob and bagasse are starch-rich 
cheap organic substances with good biodegradability. ${ }^{13}$ Liu et al. ${ }^{14}$ studied $\mathrm{PCL} /$ starch blends as carbon source and carriers for denitrification. They found that PCL/starch blends could serve as the solid carbon source for denitrification of low $\mathrm{C} / \mathrm{N}$ ratio wastewater without a nitrite accumulation. Recently, polyhydroxyalkanoates (PHA) has been widely used as carbon source and energy storage synthesized by prokaryotic microorganism in the case of carbon and nitrogen nutrient unbalance. PHA, regarded as a "biodegradable plastic", is similar to some thermoplastic materials such as polyethylene (PE) and polypropylene (PP) in mechanical properties and could be decomposed. ${ }^{15}$ Blending of straw, cob and bagasse with PHA have already been utilized to produce environmentally friendly biopolymer composite with low cost. Moreover, without the effects of extra microorganism, the microbial community of biofilm evolved only depending on the biopolymers and groundwater. However, few study has successfully explored the application of modified cellulose as slowly released carbon material for denitrification and the identification of the population related to biopolymersdegrading and denitrifying bacteria is unclear.

In the present study, the PHA/straw, cob and bagasse blend was used as carbon source and biofilm carriers for nitrate removal in permeable reactive barrier (PRB) which was operated without inocula addition for more than 3 months. The performance of bioreactor packed with PHA-based biopolymers in terms of COD release, nitrate removal, nitrite accumulation, and $\mathrm{pH}$ variation during start-up and stable operation periods was investigated. The microbial community structure and dominant species of biofilm developed only depending on the composites and groundwater were identified. These findings could be useful to provide a comprehensive basis for practical application of PHA/cellulose blend.

\section{Materials and methods}

\subsection{Composite and synthetic wastewater}

The straw, cob and bagasse were used as natural carbon material and PHA was used as skeleton carbon material. The PHA biopolymers were from the Ecomann Biotechnology Co., Ltd. in Shenzhen, China. The biopolymers were cylindrical granules with diameter and height of $2.5 \mathrm{~mm}$ and $3.5 \mathrm{~mm}$ on average, respectively. The composition of PHA-based composite was PHA $50 \%$, straw $30 \%$, cob $10 \%$ and bagasse $10 \%$. The synthetic wastewater (SWW) was prepared with the components of $\mathrm{KH}_{2} \mathrm{PO}_{4}\left(3 \mathrm{mg} \mathrm{L}{ }^{-1}, \geq 99.5 \%\right), \mathrm{K}_{2} \mathrm{HPO}_{4}\left(3 \mathrm{mg} \mathrm{L}{ }^{-1}, \geq 99.0 \%\right)$, $\mathrm{KNO}_{3}(\geq 99.0 \%)$ and sodium acetate $(\geq 99.0 \%)$ at desired concentrations (Table 1). The $\mathrm{pH}$ of the SWW was measured at 7.2-7.5.

\subsection{Experimental set up and operation}

A cylinder with a height of $80 \mathrm{~cm}$ and a diameter of $10 \mathrm{~cm}$ and working volume of $1.5 \mathrm{~L}$ was set up in PRB mode for denitrification operation (Fig. 1). The apparatus was composed of A, B, C parts with different functions. Part A was a rough sand layer with thickness of $5 \mathrm{~cm}$ and particle size of 0.5-1.0 $\mathrm{mm}$, playing a part in filter, buffer and protection. The initial sand in the flow tank was pretreated with $10 \mathrm{mg} \mathrm{\textrm {L } ^ { - 1 }}$ nitrate-contaminated groundwater for 1 month. Part B was filled with fine sand with thickness of $10 \mathrm{~cm}$ and sand size of less than $0.25 \mathrm{~mm}$. Part $\mathrm{C}$ was the main body of the reactor, filled with the composite of silica sand and PHA-based composite material and its thickness was $45 \mathrm{~cm}$. Both inlet and outlet were covered by mesh plug in order to prevent silica sand from blocking the pipeline. The reactor was operated at room temperatures $13-15{ }^{\circ} \mathrm{C}$ without deliberate control of reactor temperature to simulate groundwater environment. Black cloth enclosure was used to shield the light in order to inhibit growth of photosynthetic bacteria. Bioreactor was fed with simulation wastewater by peristaltic pump and effluent was discharged from overflow. The reactor was started up without inocula at a hydraulic retention time (HRT) of $24 \mathrm{~h}$. The level of dissolved oxygen (DO) in the influent was $1.4-1.8 \mathrm{mg} \mathrm{L}^{-1}$.

Sampling of influent and effluent was taken every day and the contents of COD, nitrate, nitrite, and $\mathrm{pH}$ were monitored. All the samples were passed through $0.45 \mathrm{~mm}$ syringe filters before analysis. During a steady-state operation on day 65, biofilm samples were taken for analysis of microbial community. To analyze the performance of straw, cob and bagasse in terms of slowly released carbon material, the pretest was conducted. Straw, cob and bagasse were soaked in $500 \mathrm{~mL}$ conical flask by the mass ratio of solid and liquid $1: 8$, respectively. The supernatant were took after 24 hours and tested in terms of $\mathrm{pH}$, color and static slowly release carbon performance.

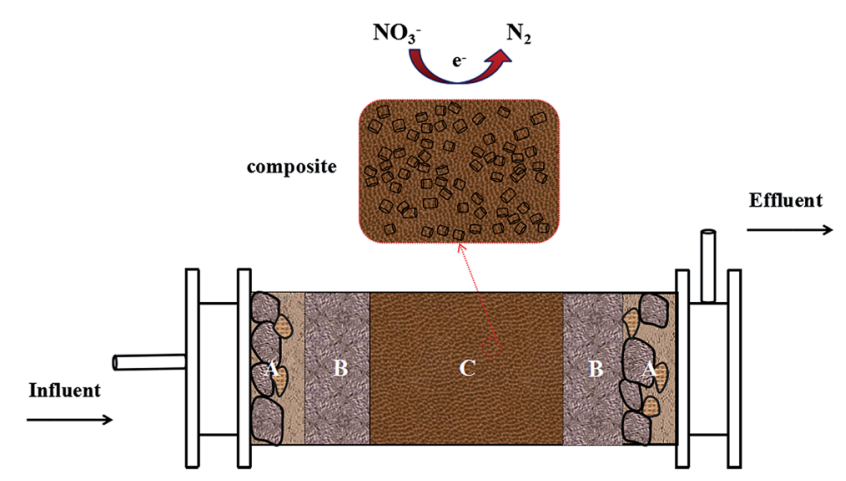

Fig. 1 Schematic diagram of the experimental setup.

Table 1 Operational parameters applied during different cultivation phase

\begin{tabular}{|c|c|c|c|c|c|}
\hline Phases & $\mathrm{I}$ & II & III & IV & $\mathrm{V}$ \\
\hline Time (day) & $1-10$ & $11-30$ & $31-40$ & $41-53$ & $54-70$ \\
\hline Influent nitrate concentration $\left(\mathrm{mg} \mathrm{L}^{-1}\right)$ & 500 & 300 & 100 & 50 & 0 \\
\hline Influent NaAC concentration $\left(\mathrm{mg} \mathrm{L}^{-1}\right)$ & $640-130$ & $130-0$ & 0 & 0 & 0 \\
\hline Hydraulic retention time $(\mathrm{h})$ & 24 & 24 & 24 & 24 & 24 \\
\hline Nitrate loading rate $\left(\mathrm{kg} \mathrm{m}^{-3} \mathrm{~d}^{-1}\right)$ & $0.025-0.075$ & 0.15 & 0.3 & 0.375 & 0.45 \\
\hline
\end{tabular}




\subsection{Analytical methods}

Samples taken from the reactor was passed through a $0.22 \mathrm{~mm}$ filter (ANPEL Laboratory Technologies Inc., Shanghai, China) before analysis. Concentrations of $\mathrm{NO}_{3}{ }^{-}-\mathrm{N}, \mathrm{NO}_{2}{ }^{-}-\mathrm{N}$ and COD were analyzed according to China SEPA Standard Methods (SEPA 2002). The $\mathrm{pH}$ values were measured by a portable multiparameter metre (Horiba B-212, Japan).

\subsection{Microbial community structure analysis}

The microbial community structure of the PHA/straw, cob and bagasse blend was profiled using high-throughput sequencing technology. The stable performance was achieved after 60 days' operation, as indicated by slight variation in effluent concentration of nitrate, nitrite and $\mathrm{pH}$. In order to ascertain the stability of microbial community structure, sludge was sampled twice, on day 60 and day 70, respectively. About $1 \mathrm{~g}$ sludge samples were taken from both reactors, and then poured by phosphate-buffered saline ( $\mathrm{pH}$ 7.4). Genomic DNA was extracted separately from the sludge samples using the FastDNA® spin kit for soil (MP Bio-medicals, USA) according to the manufacturer's instructions. DNA concentration and purity were determined by NanoDrop®ND-1000 (NanoDrop Technologies, Wilmington, DE, USA) to make sure the sample concentration higher than $20 \mathrm{ng} \mu \mathrm{L}^{-1}$ and $A_{260} / A_{280}$ between 1.80 and 2.00. Afterwards, the extracted DNA was amplified by polymerase chain reaction (PCR) using TaKaRa Ex Taq ${ }^{\circledR}$ (TaKaRa Bio Japan) on the base of the manufacturer's instruction. PCR was performed in triplicate $20 \mu \mathrm{L}$ mixtures containing $4 \mu \mathrm{L}$ of 5 $\times$ FastPfu buffer, $2 \mu \mathrm{L}$ of $2.5 \mathrm{mM}$ dNTPs, $0.8 \mu \mathrm{L}(5 \mu \mathrm{M})$ of each primer, $0.4 \mu \mathrm{L}$ of FastPfu polymerase, as well as $10 \mathrm{ng}$ of template DNA. The V4 region of bacterial 16S rRNA genes was PCR-amplified at $98^{\circ} \mathrm{C}$ for $5 \mathrm{~min}$, followed by 20 cycles at $98^{\circ} \mathrm{C}$ for $30 \mathrm{~s}, 50{ }^{\circ} \mathrm{C}$ for $30 \mathrm{~s}$, and $72{ }^{\circ} \mathrm{C}$ for $40 \mathrm{~s}$, with a final extension at $72{ }^{\circ} \mathrm{C}$ for $10 \mathrm{~min}$. The sequencing PCR products were pooled and purified using Qubit 2.0 Fluorometer (Life Technologies, Grand Island, USA). The high-throughput sequencing (Illumina MiSeq) were performed on an Illumina MiSeq platform. DNA library building and data analysis were performed in according to Jiang et al. ${ }^{16}$

\section{Results and discussions}

\subsection{The performance of nitrate removal}

The static analysis of straw, cob and bagasse and PHA are illustrated in Table 2. The $\mathrm{pH}$ in all samples were about 6.5, closed to that of distilled water. The performance of slowly released carbon using straw was much better than others, with

Table 2 The static experiment of mixing materials

\begin{tabular}{lllll}
\hline Material & $\mathrm{pH}$ & Temperature, $^{\circ} \mathrm{C}$ & Color & $\mathrm{COD}, \mathrm{mg} \mathrm{L}^{-1}$ \\
\hline Straw & 6.44 & 32 & Brown & 66.95 \\
Cob & 6.52 & 32 & Deep yellow & 40.12 \\
Bagasse & 6.31 & 32 & Henna & 40.65 \\
PHA & 6.55 & 32 & - & -
\end{tabular}

a COD concentration of $66.95 \mathrm{mg} \mathrm{L}^{-1}$. In addition, the $\mathrm{pH}$ in skeleton material of PHA was almost 6.55 which also closed to distilled water.

The COD release and nitrite accumulation were observed in PHA/straw, cob and bagasse reactor (Fig. 2). The COD concentration in effluent was always higher than that in influent. The COD concentration in effluent decreased accordingly with time, indicating the consumption of composite. Afterwards, the COD concentration in effluent decreased gradually, fluctuating between 50-100 $\mathrm{mg} \mathrm{L}^{-1}$. It is well-known that the solid biopolymers are firstly hydrolyzed to soluble monomers, dimers, or trimers, etc., which could be used as carbon source for denitrification and microbial growth. The high leaching concentration of DOC during the start-up period will favour the formation and growth of biofilm. After almost 23 days, the carbon sources released by the composite could be used as single carbon sources as the influent glucose was $0 \mathrm{mg} \mathrm{L}^{-1}$, suggesting that PHA, straw, cob and bagasse blend would be serviced as solid carbon sources for denitrification in treating nitrate polluted groundwater for almost 55 days. The remaining carbon concentration slowly decreased with time due to decreased carbon mass in the PRB system. The COD concentration decreased from $220 \mathrm{mg} \mathrm{L}^{-1}$ (day 9) to $65 \mathrm{mg} \mathrm{L}^{-1}$ (day 70) in PRB system. However, such concentrations is still considered to be too high. In theory, assuming that sucrose is the main carbon source and its content in the molasses was about $65 \%$, $133 \mathrm{mg} \mathrm{L}^{-1}$ of nitrate can be removed by about $74 \mathrm{mg} \mathrm{L}^{-1}$ of COD into the level below the groundwater quality standard (44 $\mathrm{mg} \mathrm{\textrm {L } ^ { - 1 }}$ ) recommended by the WHO. ${ }^{17}$ Excessive carbon remaining after denitrification in groundwater is not desirable in terms of remedial cost. More importantly, this may lead to potential secondary environmental problems. Detailed investigation regarding the optimum number of SRM barriers to minimize remaining molasses concentration is required. The initial addition of glucose could enhance the efficiency in removing nitrate polluted groundwater in the startup of the reaction, suggesting that glucose as $s$ is an important carbon source in denitrification, especially in the endogenous decay. ${ }^{\mathbf{1 8}}$

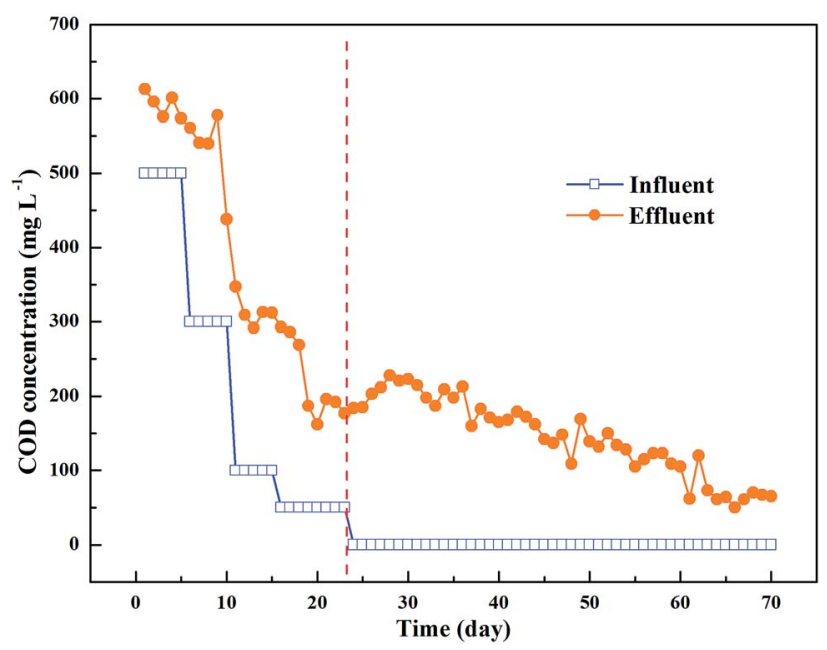

Fig. 2 Variation of COD concentration during 70 days' operation. 
Fig. 3 depicts the denitrification performance of the PHA/ straw, cob and bagasse blend without inocula in terms of effluent nitrate concentration. Initially, the nitrate concentration in the influent was about $10 \mathrm{mg} \mathrm{L}^{-1}$ (Fig. 3A). A removal rate of almost $100 \%$ was observed, as the $\mathrm{NO}_{3}{ }^{-}-\mathrm{N}$ concentration in the effluent maintained close to $0 \mathrm{mg} \mathrm{L}^{-1}$ (Fig. 3B). As the nitrate loading increased, higher concentration of nitrate was
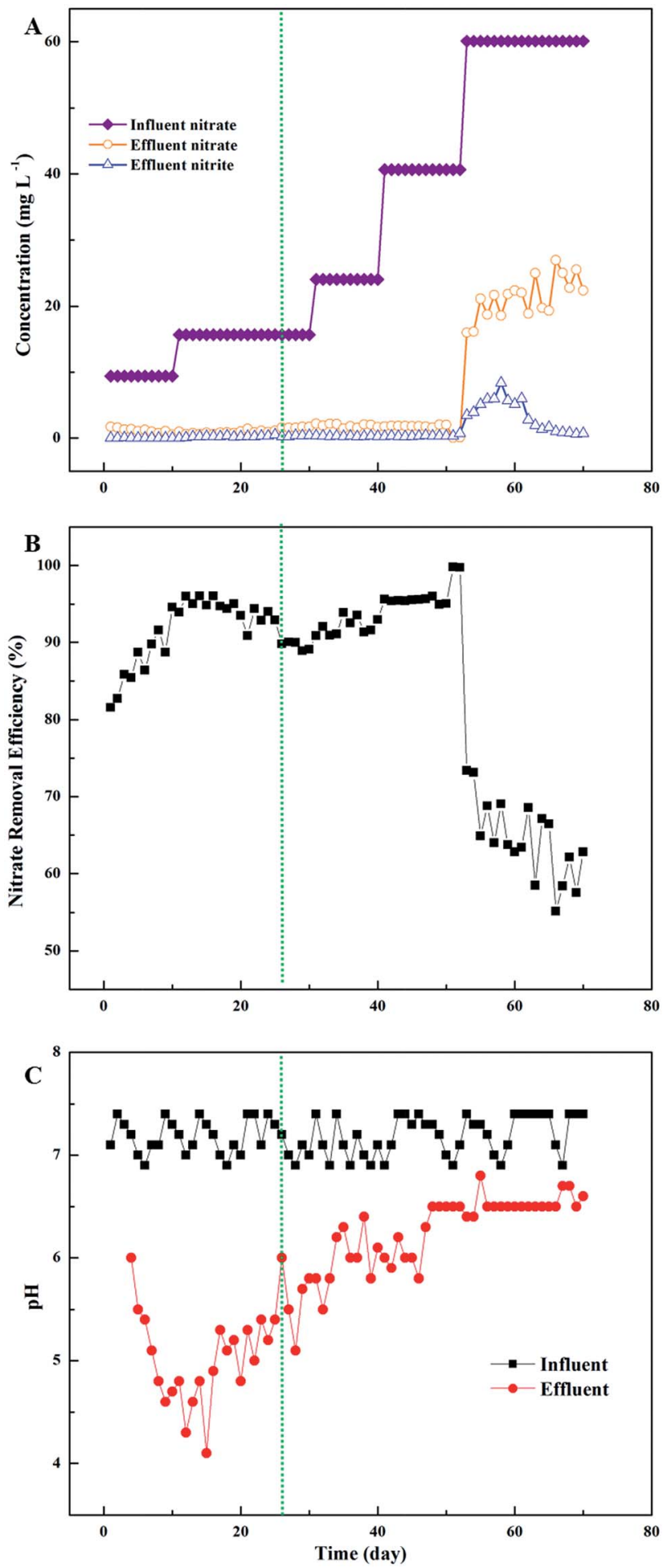

Fig. 3 Nitrate degradation performance during 70 days' operation. observed in the effluent and the removal rate fell to almost $70 \%$. A gradual decline in effluent nitrate concentration accompanied by progressive increase in influent nitrate concentration were observed, suggesting the progressive enrichment of denitrifying bacteria and improvement of nitrate removal efficiency. With the consumption of the carbon sources released by the composite and the improvement of nitrate loading, a significant decrease in nitrogen removal was therefore observed during these days. After 53 days' operation, the nitrate removal efficiency fell to $20-30 \%$. The reason of the poor nitrate removal efficiency could be explained by the consumption of the slowrelease carbon sources. Compared with other studies, ${ }^{7,8}$ the composite of natural material and PHA showed robust performance of nitrate removal without regular addition of fresh composite. In addition, this experimental result provides a new approach for the moderate dosage of PHA on the calculation of the COD concentration and nitrate concentration in effluent. The addition of glucose played an important role in startup period, because the lag time was minimized by the composite. Compared with previous studies, ${ }^{5,19,20}$ the combination of glucose and polymer material could minimize lag period of reaction, which could decrease the effluent nitrate concentration.

In the meantime, both of the production of nitrite and the decrease of $\mathrm{pH}$ value could reflect the denitrification effect. ${ }^{21}$ Both the concentration of nitrite and the intermediate of the denitrification process were detected during the experiment. Biologic denitrification is the sequential microbial reduction of nitrate to dinitrogen gas, through intermediates such as nitrite, nitric oxide and nitrous oxide. As the effluent stabilized, nitrite concentration fluctuated in $\mathbf{0}-\mathbf{1} \mathrm{mg} \mathrm{L}^{-1}$, which basically met the requirements of the third sort of "The Quality Standard of Underground Water" in China (GB/T14848-93). The $\mathrm{pH}$ in the system played a role in denitrification by influencing the growth of denitrifying microorganisms and expression and activity of denitrifying enzymes. Precious studies have shown that the denitrification rates decrease in soils with low $\mathrm{pH}$ values. $^{22}$ Noticeably, PHA may be thought to act by adjusting the system pH. Fig. 3C showed that the pH buffering ability increased with the presence of PHA. The $\mathrm{pH}$ value in the effluent reduced to 57, while the $\mathrm{pH}$ value in the influent was set at nearly 7.4. The combination of hydroxide ion and positive ions caused by denitrification, which could lead to the decrease of $\mathrm{pH}$. Similar results of denitrification in polluted groundwater were analyzed by Mergaert et al. ${ }^{23}$ and Kim et al. ${ }^{21}$ The increase of $\mathrm{pH}$ value indicates the deterioration of the system and running out of the slow-release carbon sources material.

\subsection{Microbial community structure and dominant species analysis}

Biofilm attached and grew gradually on the carrier without inocula added into the bioreactor. In this study, the microbial community structure on the composite of the natural source and slow-release carbon source materials in the PBR system were analyzed by high-throughput sequencing on Illumina Miseq system with the dominant bacteria revealed. A total 
amount of 20836 effective sequence tags were obtained through primer and barcodes matching with raw reads and a series of filtering process. The observed number of operational taxonomic units (OTUs) at a 3\% distance was 3699. As a metric for species richness, the estimated total number of OTUs by analyzer of Chao were 16 384.40. The Ace of 35353.28 and Shannon of 5.18 indices usually applied to exhibit more complex community richness and diversity. This indicates that PHA-based composite has great effects on the biodiversity of biofilm bacteria.

As shown in Fig. 4, bacterial sequences affiliated with Proteobacteria $(62.16 \%)$ were the most abundant, followed by the sequences affiliated with Firmicutes (17.86\%), Bacteroidetes (5.97\%), Actinobacteria (5.56\%), Acidobacteria (2.96\%), Chloroflexi $(1.31 \%)$, others $(0.69 \%)$, and Verrucomicrobia $(0.62 \%)$. This result is similar with the study using PCL as carbon source with activated sludge as inocula, ${ }^{2}$ showing that Proteobacteria was the most abundant bacteria (with over $80 \%$ of total sequences).

There are two co-existed processes in the solid-phase denitrification system, including the degradation and denitrification of biopolymer. The first and important step is the hydrolysis of the solid biopolymers by extracellular enzymes excreted by degrading microorganisms. The second step is the utilization of degradation products by denitrifying bacteria. The Gram negative Proteobacteria represent a large group of bacteria, including a broad variety of aerobic and anaerobic bacteria. They could degrade a wide spectrum of organic substances and have been commonly detected in the wastewater treatment system. ${ }^{24}$ Some strains affiliated with phylum Firmicutes were reported to produce extracellular enzymes such as cellulose, lipase and protease, which facilitate the hydrolyzation and utilization of the solid biopolymers.

At the genus level, the majority of the dominant populations contributed to Azospira (24.10\%), Rhizomicrobium (12.74\%), Acidovorax (6.70\%), Dechloromonas (3.00\%), Clostridium III $(2.32 \%)$, and Clostridium sensu stricto (1.33\%). Both the richness and diversity of bacterial were relatively low, probably due to the selective pressure placed on the bacterial community by nitrate as the sole nutrition.

The genera Azospira and Rhizomicrobium were the most predominants in the system, which might be responsible for denitrification because nitrate was effectively removed in this system at relative high nitrate loading. Previous study had revealed that Rhizomicrobium could utilize nitrate as electron acceptors and reduce it to nitrite in the presence of glucose. ${ }^{25}$ After the supply of glucose was removed, Rhizomicrobium still existed which could utilize the carbon source released by the composite to keep the high nitrate removal efficiency. As nitrogen-fixing is an energy intensive process, ${ }^{3}$ and the presence of Azospira could provide the reducing power for denitrification. Bae $e t a l{ }^{3}$ also found that the presence of Azospira could purify water because the $\beta$-hydroxybutyric acid which produced by anaerobic digestion could be consumed by Azospira. In addition, the bacterial strain Acidovorax could also utilize such as ethanol, methanol, sodium acetate, glucose and poly(e-caprolactone) as carbon sources in biological nitrate removal. ${ }^{26}$ Dechloromonas was also found to have great potential with the use of inexpensive molasses to remediate Se-contaminated agricultural drainage water containing relatively high nitrate levels. ${ }^{27}$ Based on the analysis of high throughput sequencing, dominant species were denitrifying bacteria resulting in high nitrate removal efficiency. In addition, previous studies have showed that PHA or glycogen in the bacterial cells could potentially drive denitrification. ${ }^{\mathbf{1} 28}$ Among all the biodegradable polymers (BDPs) that are currently available for denitrification, PHA are easily degraded and have shown high nitrogen removal rates. ${ }^{5,23,29}$

\subsection{Cost evaluation}

The cost of PHA-based biopolymers according to their denitrification capacity, compared with biodegradable polymer PCL, PHBV-based biopolymers and soluble carbon source methanol commonly used was presented in Table 3 . The unit price of the substrate materials refers to the price of domestic products in China. The consumption of substrates are almost similar with
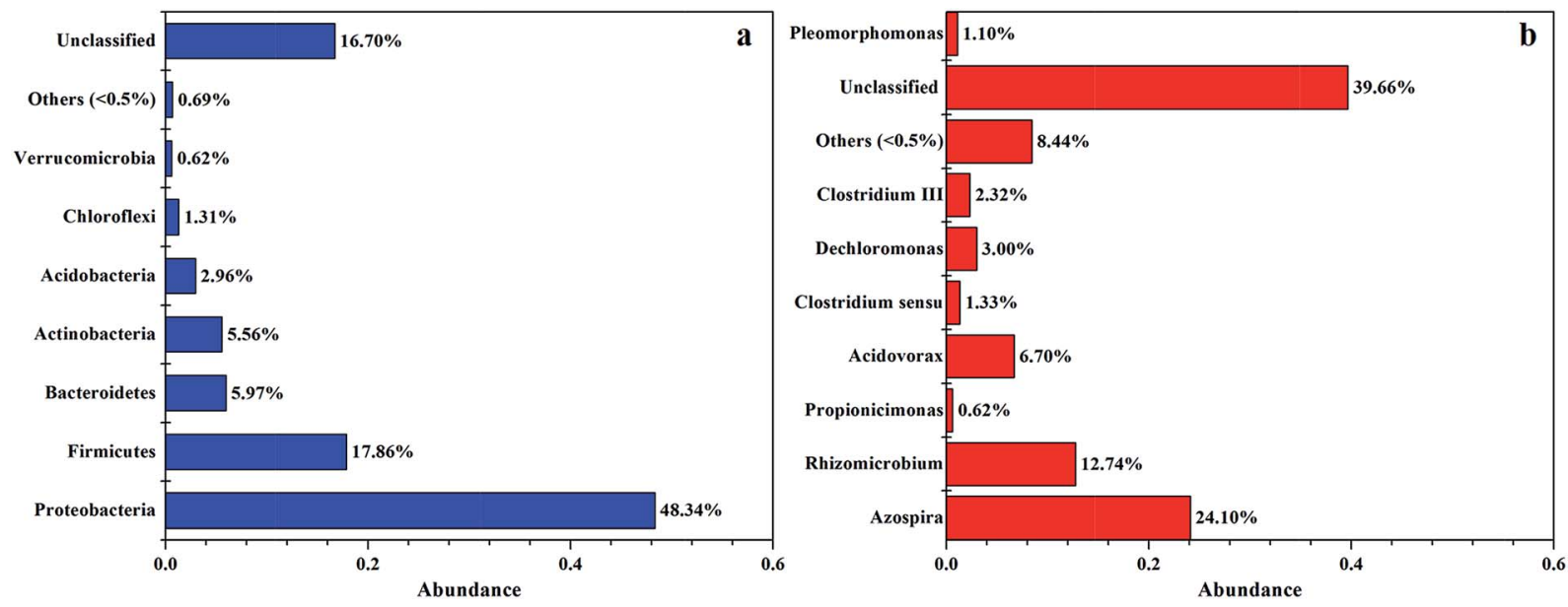

Fig. 4 Phylogenetic distribution of sequences assigned on phylum (a) and genus (b) in PRBs. 
Table 3 Estimated costs of carbon source for nitrate removal

\begin{tabular}{|c|c|c|c|c|}
\hline Substrate & $\begin{array}{l}\text { Price of substrate } \\
\text { (CNY per kg) }\end{array}$ & $\begin{array}{l}\text { Consumption of substrate } \\
\left(\mathrm{kg} \text { per } \mathrm{kg} \mathrm{NO}_{3}{ }^{-}-\mathrm{N}\right)\end{array}$ & $\begin{array}{l}\text { Cost of denitrification (CNY } \\
\left.\text { per } \mathrm{kg} \mathrm{NO}_{3}{ }^{-}-\mathrm{N}\right)\end{array}$ & Reference \\
\hline PHA, straw, cob and bagasse & 8 & $2.50-3.20$ & $20.00-25.60$ & This study \\
\hline PHBV/bamboo powder & 15.5 & $1.69-1.86$ & $26.20-28.80$ & \\
\hline PCL & 27 & $1.60-3.70$ & $43.20-99.90$ & 6 \\
\hline Methanol & 2.5 & $2.08-3.98$ & $5.20-10.00$ & 4 \\
\hline
\end{tabular}

methanol, while the cost of the biopolymers for denitrification was 5-10 times higher than methanol due to high unit price. The availability of economic biopolymers is significant for the adoption of this material as carbon source for denitrification. It is clear that the PHA/straw, cob and bagasse composite is more cost effective than other biopolymers available and promising for practical application.

\section{Conclusions}

PHA, straw, cob and bagasse composite was used as carbon source and biofilm carrier for denitrification in PRB system without inocula. The removal efficiency of $60 \mathrm{mg} \mathrm{L}^{-1}$ of nitrate kept around $55-70 \%$ in this experiment. The slow-release carbon characteristics of modified cellulose from the PRB system provided a long-term and stable operation. The denitrifying bacteria and biopolymer-degrading bacteria, was the most dominant species in PHA-based composite which might explain why the PHA was more friendly to environment and produced less secondary contamination. In the light of field application, further study is required to achieve a perfect effective on the released carbon and nitrate pollution.

\section{Acknowledgements}

This work was supported by the basic scientific research expenses for the central scientific research institutes of China [No. 2015012].

\section{References}

1 H. Chen, Q. Yang, X. Li, Y. Wang, K. Luo and G. Zeng, Chemosphere, 2013, 92, 1349-1355.

2 L. Chu and J. Wang, Chemosphere, 2013, 91, 1310-1316.

3 H. S. Bae, B. A. Rash, F. A. Rainey, M. F. Nobre, I. Tiago, M. S. da Costa and W. M. Moe, Int. J. Syst. Evol. Microbiol., 2007, 57, 1521-1526.

4 A. Boley, W. R. Muller and G. Haider, Aquacultural Engineering, 2007, 22, 75-85.

5 L. B. Chu and J. L. Wang, Chemosphere, 2016, 155, 463-470. 6 J. L. Wang and L. B. Chu, Biotechnol. Adv., 2016, 34, 1103-1112.

7 M. Volokita, A. Abeliovich and M. Soares, Water Sci. Technol., 1996, 34, 379-385.

8 M. Volokita, S. Belkin and A. Abeliovich, Water Res., 1996, 30, 965-971.
9 M. I. M. Soares and A. Abeliovich, Water Res., 1998, 32, 37903794.

10 M. G. Healy, T. G. Ibrahim, G. J. Lanigan, A. J. Serrenho and O. Fenton, Ecol. Eng., 2012, 40, 198-209.

11 J. Snaidr, R. Amann, I. Huber, W. Ludwig and K. H. Schleifer, Appl. Environ. Microbiol., 1997, 63, 2884-2896.

12 Y. Tokiwa, B. Calabia, C. Ugwu and S. Aiba, Int. J. Mol. Sci., 2009, 10, 3722.

13 F. P. La Mantia and M. Morreale, Green composites: a brief review, Composites, Part A, 2011, 42, 579-588.

14 J. Liu, Z. Q. Shen, Y. X. Zhou, R. Cao and Y. Z. Li, Environ. Sci. Pollut. Res., 2015, 27, 441-446.

15 S. Y. Lee, Biotechnol. Bioeng., 1996, 49, 1-14.

16 X. B. Jiang, J. Y. Shen, Y. Han, S. Lou, W. Q. Han, X. Y. Sun, J. S. Li, Y. Mu and L. J. Wang, Water Res., 2016, 88, 257265.

17 B. S. Lee, E. Park, J. Y. Um, K. Y. Lee, K. Nam and N. C. Woo, Environ. Earth Sci., 2012, 10, 309.

18 M. Winkler, E. R. Coats and C. K. Brinkman, Water Res., 2011, 45, 6119-6130.

19 P. Elefsiniotis and D. Li, Biochem. Eng. J., 2007, 28, 148155.

20 M. A. Gómez, J. Gonzalez-Lopez and A. De La Rua, J. Environ. Sci. Health, Part A: Toxic/Hazard. Subst. Environ. Eng., 2009, 44, 1298-1305.

21 H. Kim, J. Kim, S. G. Shin, S. Hwang and C. Lee, Bioresour. Technol., 2016, 207, 440-445.

22 M. Šimek, L. Jisova and D. W. Hopkins, Soil Biol. Biochem., 2002, 34, 1227-1234.

23 J. Mergaert, A. Boley, M. C. Cnockaert, W. R. Muller and J. Swings, Syst. Appl. Microbiol., 2011, 24, 303-310.

24 E. Walters, A. Hille, M. He, C. Ochmann and H. Horn, Water Res., 2009, 43, 4461-4468.

25 K. Yumiko and W. Kazuya, Int. J. Syst. Evol. Microbiol., 2011, 61, 1781-1785.

26 O. O. Nalcaci, N. Böke and B. Ovez, Desalination, 2011, 274, 44-53.

27 Y. Q. Zhang and T. W. Frankenberger Jr, Sci. Total Environ., 2007, 372, 397-405.

28 R. Zhu, S. Wang, J. Li, K. Wan, L. Miao, B. Ma and Y. Peng, Bioresour. Technol., 2013, 128, 401-408.

29 A. Hiraishi and S. T. Khan, Appl. Microbiol. Biotechnol., 2003, 61, 103-109. 